\title{
SURFACE LEAKY WAVES AND THEIR MEASUREMENT
}

\author{
Ján Zehentner*, Jan Macháč*, Jan Mrkvica*, Marcin K. Sarnowski*, Jiří Polívka\# \\ ${ }^{*}$ Czech Technical University, Technická 2, 16627 Prague 6, Czech Republic \\ Tel +420 2 24352273, Fax +420 24355865, e-mail zeh@mbox.cesnet.cz \\ \#Spacek Labs inc., 212 East Gutierrez Street, Santa Barbara, California 93101, USA \\ Tel +1 805 5644404, Fax +1 805 9663249, e-mail spacek@silcom.com
}

\begin{abstract}
A new approach to experimental identification of surface leaky waves on printed-circuit lines is presented in this paper. Active radiometry is used for field probing even in the near field zone. The measurement is adjusted into the $X$ band. The method is demonstrated on the slotline. Consequently the line is scaled in order to investigate the 1st and 2 nd leaky waves which, on a standard-sized substrate, occur in the mm-wave range only. The high rate of polarization distinctness of the probe enables us to distinguish particular field components. We present the first very promising results.
\end{abstract}

\section{INTRODUCTION}

Familiarity with the properties of the lines used in uniplanar technology is necessary for the design of circuits in the mw and mm-wave range. This particularly concerns the slotline, the coplanar waveguide and the coplanar strips. Not only the bound wave but also surface or space leaky waves can exite on these lines. Leaky waves are usually undesirable in circuits, since they cause cross-talk and spurious effects at high frequencies, as was recently reported by Krems et al (1). The surface leaky wave in the submm-wave range displaces the bound wave, which can no longer propagate here.

In this paper we will investigate only surface leaky waves, and their behaviour will be demonstrated on the slotline. The most comprehensive analysis until now of the surface leaky wave on the slotline was given by Shigesawa et al in (2). Zehentner et al (3) presented simultaneous leakage into two surface waves on the slotline. Waves taking away power at the same time into three or four surface waves were reported by Zehentner et al in (4). There have been many theoretical treatises on leaky waves, while less attention has been paid to checking them experimentally.

Godshalk (5) detected a leaky wave on the coplanar waveguide by a fall of insertion loss in the band up to $50 \mathrm{GHz}$. Nghiem et al (6) introduced a similar measurement on the microstrip line in the $10 \mathrm{GHz}$ band. Measurement of the phase constant of the bound wave and the 1st leaky wave, including its leakage constant, was described by Shigesawa et al in (7) and applied to conductor-backed coplanar strips. Presence of the leaky wave is concluded from the observed resonances in the insertion loss on the covered finite-width conductor-backed coplanar waveguide, as shown by Liu et al (8). Measurement of the phase constant of the bound and 1st leaky waves in the operation mode with the frequency gap and with simultaneous propagation of both waves on conductor-backed coplanar strips and on the slotline was published in (2). Tsuji et al (9) published interesting measurements of the phase constant of the 1 st and 2nd leaky wave on the same line, both inside and outside the frequency gap located between them.

In this paper, we recall the complete dispersion characteristics of the bound, 1 st and 2nd leaky wave on the slotline. We introduce an enlarged model of the line suitable for investigation in the X band. We present a new measuring method verifying the leaky wave on the slotline. Active radiometry is utilized for field detection in the near zone. Finally, we give the first experimental results. It is believed that the proposed method, using a noise signal, removes some drawbacks peculiar to standard measurement with a monochromatic signal. This approach extends the methods that can be used for experimental investigation of surface leaky waves.

\section{DISPERSION CHARACTERISTICS OF THE BOUND, 1ST AND 2ND LEAKY WAVE}

Fig. 2 shows the complete dispersion characteristics of the bound wave, the 1 st and 2 nd leaky waves on the lossless laterally unlimited slotline with zero metallization thickness, the cross-section of which is shown in Fig. 1. The bound wave propagates up to frequency $\mathrm{f}_{4}$, while the 2 nd and 1 st leaky waves set in at frequency $\mathrm{f}_{3}$ and $\mathrm{f}_{5}$, respectively. The dispersion characteristics in Fig. 2 hold for the slotline on a plexiglass substrate $14.6 \mathrm{~mm}$ in thickness with permittivity 2.6 and slotwidth $5.65 \mathrm{~mm}$. A lossless substrate is assumed, since there is almost no difference between them and those characteristics valid for plexiglass with a loss factor of 0.0067 . The existence of the 1 st leaky wave alone or 
simultaneously with the bound wave was experimentally verified in (2). We now therefore intend to prove excitation of the 2 nd leaky wave, or simultaneous excitation of the 1 st and 2 nd leaky waves.

\section{ENLARGED-SCALE MODEL OF THE SLOTLINE}

The 1st and 2nd leaky waves can propagate simultaneously on the slotline with a substrate thickness of $1 \mathrm{~mm}$ and permittivity 2.5 at frequencies higher than $100 \mathrm{GHz}$. Measurement at such frequencies is difficult and expensive. Consequently we designed the slotline on an easily available plexiglass substrate with $\varepsilon_{\mathrm{r}}=2.6, \mathrm{~h}=14.6 \mathrm{~mm}$ and $\mathrm{w}=5.65$ $\mathrm{mm}$, on which both the 1st and 2nd leaky waves can propagate in the X band, Fig. 2. The second designed slotline with $\varepsilon_{\mathrm{r}}=2.6, \mathrm{~h}=10.0 \mathrm{~mm}$ and $\mathrm{w}=6.0 \mathrm{~mm}$ allows propagation of the $1 \mathrm{st}$ leaky wave above $10 \mathrm{GHz}$. The influence of the substrate loss factor $\operatorname{tg} \delta=0.0067$ on the dispersion characteristics in the $\mathrm{X}$ band is negligible in comparison with expected total measuring errors. The lateral edges of the substrate are beveled and absorbent cladded.

\section{MEASURING METHOD}

In the experiments published in (2,5-9), the leaky wave was detected either by $\left|\mathbf{s}_{21}\right|$ measurement or by field probing along the substrate surface. The first method indicates the presence of the leaky wave. The second requires a properly sized probe, exclusion of possible reflections, effective slotline feed, and excitation of the desired wave. These restrictive requirements can be avoided when the following arrangement is set up. A simple dipole, movable over the substrate fed by a noise diode in the middle, emits radiation. A radiometer with a rectangular waveguide input placed on the metallization across the slot directly receives the noise signal. The center frequency of the receiver is $10.75 \mathrm{GHz}$, and the bandwidth equals $\pm 0.25 \mathrm{GHz}$. The output reading is proportional to the noise power. In this way we obtain the magnitude of the field in relative units, not the phase. Such an arrangement has the advantage of probing the near zone field close to the receiver. A practical disadvantage of this method is the need to tune the radiometer in order to obtain the frequency dependence of the propagation constant. A number of problems arose during measurement. We therefore also applied a monochromatic signal, in order to compare the already known method with the new method using the noise signal.

\section{EXPERIMENTAL RESULTS}

Since it is customary to speak about feeding the line and detecting the excited field, we will now for a moment exchange the roles of the probe and the receiver. Regardless of efficiency, the waveguide feed mentioned above is suitable for exciting leaky waves on the slotline. The phase and the leakage constants of the 2nd leaky wave at $10.75 \mathrm{GHz}$ change less than $3 \%$ with a frequency shift of $\pm 0.25 \mathrm{GHz}$ for a line on the substrate which is $14.6 \mathrm{~mm}$ in thickness. The corresponding leakage angles change by $0.75 \%$ in the same frequency span while, for the 1 st leaky wave, it changes by less than $1.2 \%$. Consequently the leakage constant $\alpha$ can be compared with the value determined from the field attenuation measured along the slot, which varies as $\mathrm{e}^{-2 \alpha z}$. The phase constant $\beta$ can be checked by means of the leakage angles, related with the $\mathrm{TM}_{0}$ and $\mathrm{TE}_{1}$ surface waves, found from the direction of movement of the respective field sidemaximum raised due to the finite size of the source and the substrate.

The calculated and measured $\left|E_{x}\right|^{2}$ field component along the slot on the slab $10 \mathrm{~mm}$ in thickness for the 1st leaky wave is shown in Fig. 3. The leakage constant $27.039 \mathrm{~Np} / \mathrm{m}$ compares well with the computed value of $25.5 \mathrm{~Np} / \mathrm{m}$. A similar field record for the slotline on a plexiglass slab $14.6 \mathrm{~mm}$ in thickness at $10.75 \mathrm{GHz}$ is plotted in Fig. 4 . Now $\mathrm{E}_{\mathrm{x}}$ is a superposition of the 1 st and 2nd leaky waves propagating simultaneously. Their amplitudes are not known in advance. The bold line representing measured record has been fitted with the thin line representing the superposition of two waves with an amplitude ratio $\mathrm{E}_{1} / \mathrm{E}_{2}=5 / 240$ associated with the 1 st and 2nd leaky waves. Their calculated propagation constants are $\gamma_{1}=3.37-\mathrm{j} 325.38 \mathrm{~m}^{-1}$ and $\gamma_{2}=30.36-\mathrm{j} 262.23 \mathrm{~m}^{-1}$. Obviously the 2nd leaky wave is launched dominantly, so its leakage constant is checked properly.

The angle of leakage into the $\mathrm{TM}_{0}$ surface wave by the 1 st leaky wave and the angles of the leakage for the 2 nd leaky wave taking power away into the $\mathrm{TM}_{0}$ and $\mathrm{TE}_{1}$ surface waves are given in Fig. 5. The solid lines represent the calculated angles, while the squares mark out the measured positions of the $\left|E_{\mathrm{x}}\right|^{2}$ maximums.

Measuring the leaky waves is difficult, since several effects manifest at the same time. For example, reflections from the sides of the substrate, simultaneous excitation of the 1st and 2nd leaky wave, the field distribution close to the slot, direct radiation of the source, etc. A comparison between the $\left|E_{x}\right|^{2}$ field component record taken along the slot by a monochromatic signal and by the noise signal confirmed the advantage of the latter over the former method for this purpose. For this test we used a slotline made on a teflon substrate with $\mathrm{w}=3.3 \mathrm{~mm}, \mathrm{~h}=4.4 \mathrm{~mm}, \varepsilon_{\mathrm{r}}=2.08$ and $\operatorname{tg} \delta=0.0004$ when only a pure bound wave propagates in the X band. 


\section{CONCLUSIONS}

A new measuring method has been designed for identifying surface leaky waves on open printed-circuit lines. The idea has been demonstrated on the slotline. The measured field-map confirms the presence of the first and second leaky wave. The field was probed on an enlarged line suitable for testing in the $\mathrm{X}$ band. Our next objective is to exclude particular disturbing effects, to add precision to the measurements, to ensure unambiguous results and to simplify the procedure.

\section{ACKNOWLEDGMENTS}

We gratefully acknowledge the scholarship granted by the Faculty of Electrical Engineering of the Czech Technical University in Prague to M. K. Sarnowski, a student of the Technical University of Gdansk, supporting his participation in this project. The work was done on the SP-2 computer at the Joint Supercomputer Center of the Czech Technical University, University of Chemical Technology and IBM Prague.

\section{REFERENCES}

[1] T. Krems, A. Tessmann, W. H. Haydl, C. Schmelz, P. Heide: Avoiding cross talk and feedback effects in packaging coplanar millimeter-wave circuits. IEEE MTT-S Internat. Microwave Symp. Digest, IEEE, Baltimore, MD, 1998, vol. 2, pp.1091-1094.

[2] H. Shigesawa, M. Tsuji, A. A. Oliner: Simultaneous propagation of bound and leaky dominant modes on printedcircuit lines: A new general effect. IEEE Trans. Microwave Theory Techn., vol. 43, 1995. no. 12, pp. 3007-3019.

[3] J. Zehentner, J. Macháč, M. Migliozzi: Upper cut-off frequency of the bound wave and new leaky wave on the slotline. 1997 IEEE MTT-S Internat. Microwave Symp. Digest, IEEE, Denver, CO, 1997, vol. 2, pp. 487-490.

[4] J. Zehentner, J. Macháč, M. Migliozzi: Dispersion characteristics of leaky waves on lossless and lossy slotlines. IEEE MTT-S Internat. Microwave Symp. Digest, IEEE, Baltimore, MD, 1998, vol. 3, pp. 1795-1798.

[5] E. M. Godshalk: Generation and observation of surface waves on dielectric slabs and coplanar structures. 1993 IEEE MTT-S Internat. Microwave Symp. Digest., IEEE, Atlanta, GA, 1993, pp. 923-926.

[6] D. Nghiem, J. T. Williams, D. R. Jackson, A. A. Oliner: Existence of a leaky dominant mode on microstrip line with an isotropic substrate: Theory and measurement. 1993 IEEE MTT-S Internat. Microwave Symp. Digest, IEEE, Atlanta, GA, 1993, pp. 1291-1294.

[7] H. Shigesawa, M. Tsuji, A. A. Oliner: Theory and experiments of simultaneous propagation of both bound and leaky dominant modes on conductor-backed coplanar strips. Proceedings of the 23rd European Microwave Conference, Reed Exhibition Companies (UK), Madrid 1993, pp. 1005-1008.

[8] Y. Liu, K. Cha, T. Itoh: Non-leaky coplanar (NLC) waveguides with conductor backing. IEEE Trans. Microwave Theory Techn., vol. 43, 1995, no. 5, pp. 1067-1072.

[9] M. Tsuji, H. Shigesawa, H. Sannomiya, A. A. Oliner: Spectral gap when power leaks into more than one type of surface wave on printed-circuit lines. 1997 IEEE MTT-S Internat. Microwave Symp. Digest, IEEE, Denver, CO, 1997, pp. 483-486.

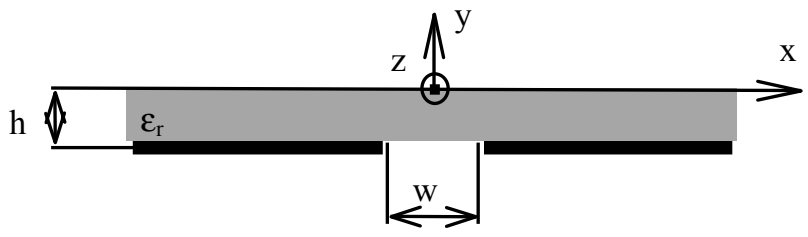

Fig. 1 Cross-section of the slotline 

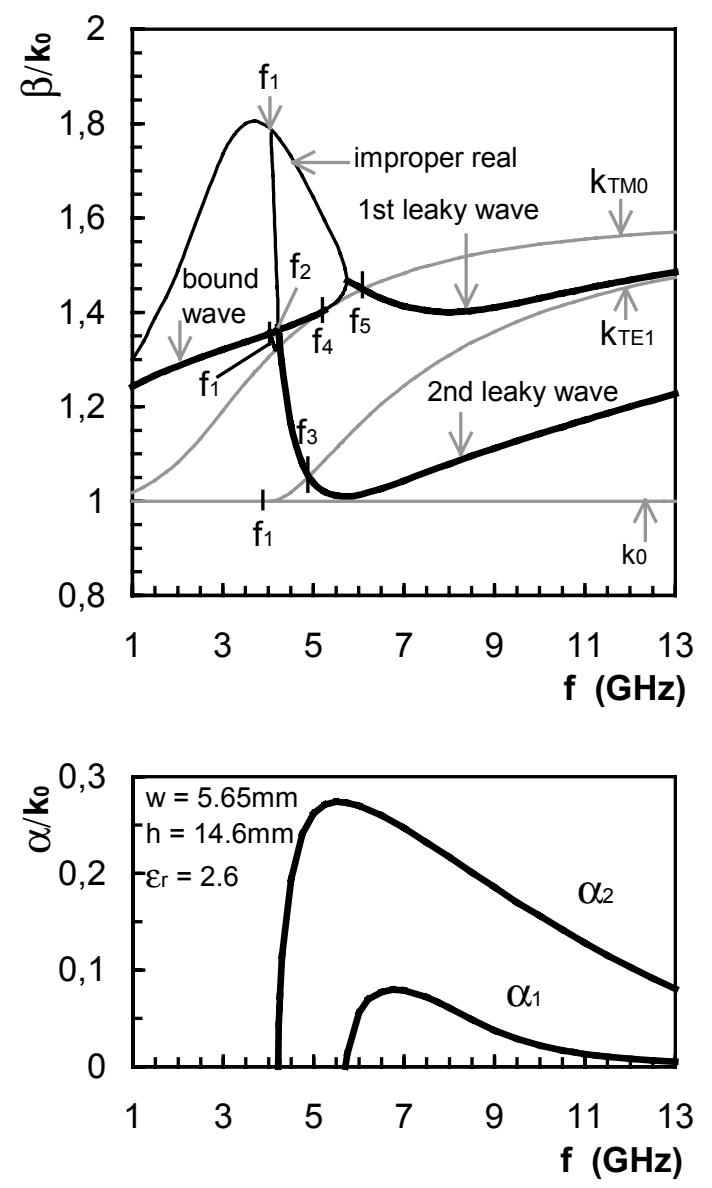

Fig. 2 Normalized phase $\beta / \mathrm{k}_{0}$ and leaky $\alpha / \mathrm{k}_{0}$ constants as a function of frequency $\mathrm{f}$ for the slotline on a plexiglass substrate with $\mathrm{w} / \mathrm{h}=0.387$ and $\varepsilon_{\mathrm{r}}=2.6$.

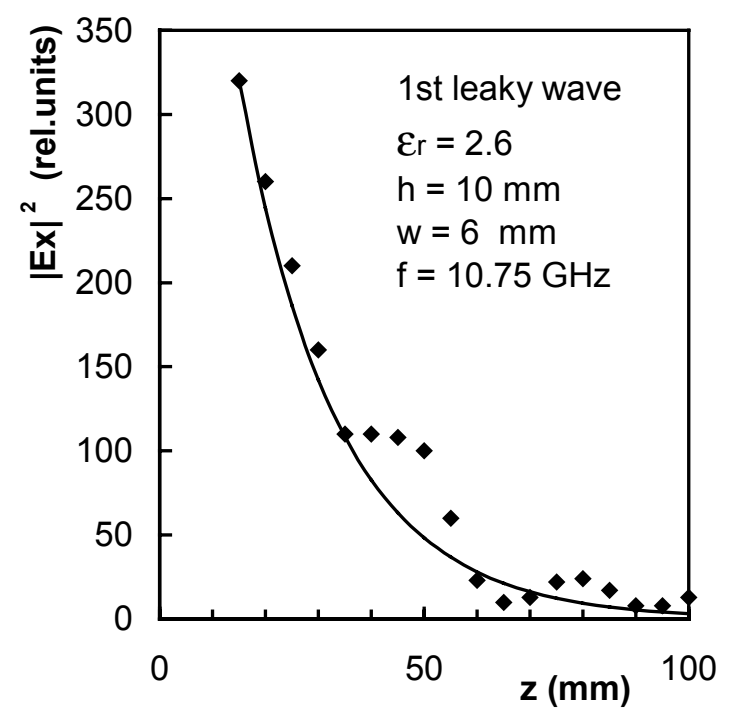

Fig. $3\left|E_{x}\right|^{2}$ field component calculated and measured by the noise radiator along the slot at the center frequency of $10.75 \mathrm{GHz}$ of the radiometer for the 1 st leaky wave on a $10 \mathrm{~mm}$ thick plexiglass slab with $\mathrm{w}=6.0 \mathrm{~mm}$.

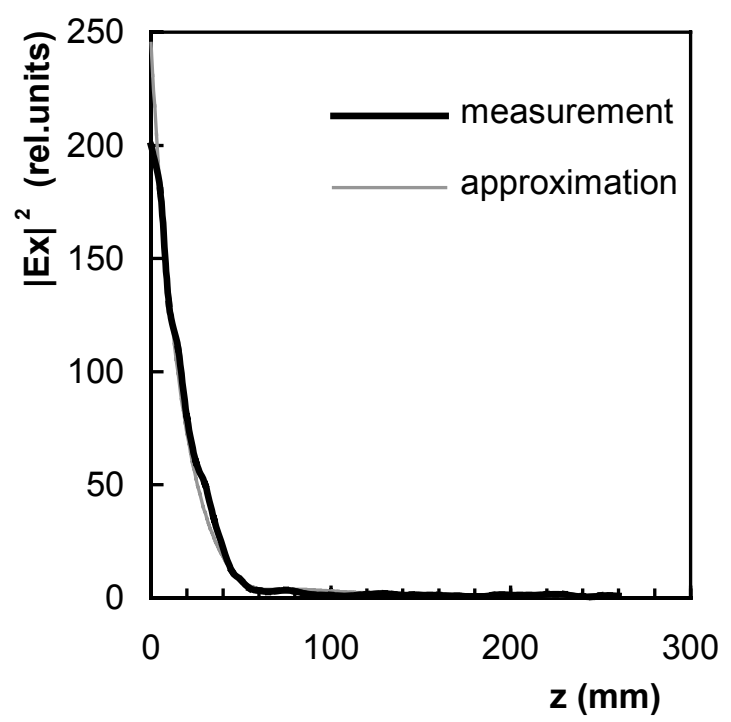

Fig. $4\left|E_{x}\right|^{2}$ component of the field measured along the plexiglass slotline with $\mathrm{w}=5.65 \mathrm{~mm}$ and $\mathrm{h}=14.6 \mathrm{~mm}$ by the noise radiator with a center frequency of $10.75 \mathrm{GHz}$ of the radiometer and an approximation of this field by superposition of two leaky waves.

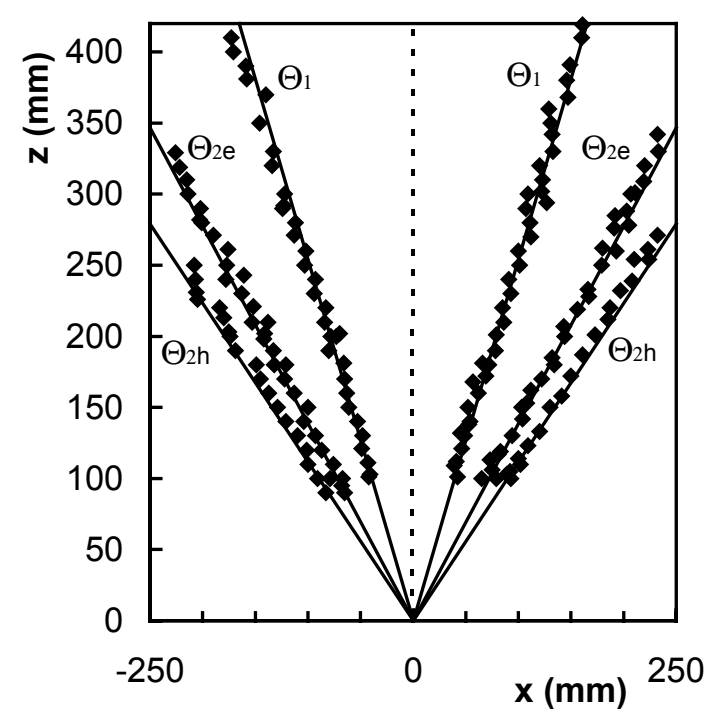

Fig. 5 Calculated and measured leakage angles, $\Theta_{1}$ for the $1 \mathrm{st}$ and $\Theta_{2 \mathrm{e}}, \Theta_{2 \mathrm{~h}}$ for the 2nd leaky wave on a $14.6 \mathrm{~mm}$ thick plexiglass substrate with a $5.65 \mathrm{~mm}$ slotwidth at $10.75 \mathrm{GHz}$. 